\title{
The Association of Psychosocial Risk Factors with the Burnout Syndrome in Dentists in Guadalajara, Jalisco Mexico
}

\author{
María de Lourdes Preciado-Serrano, Elizabeth Pozos-Radillo, \\ Ana Rosa Plascencia-Campos, Cecilia Colunga-Rodríguez \\ University Center for Health Sciences, University of Guadalajara, Guadalajara, Mexico \\ Email: malourdespre@gmail.com
}

Received 3 February 2016; accepted 4 March 2016; published 7 March 2016

Copyright (C) 2016 by authors and Scientific Research Publishing Inc.

This work is licensed under the Creative Commons Attribution International License (CC BY). http://creativecommons.org/licenses/by/4.0/

c) (i) Open Access

\begin{abstract}
The purpose of this study was to determine the association of psychosocial risk factors with the burnout syndrome in 144 dentists. Semi structured interviews were made and the Maslach Burnout Inventory and the Psychosocial Risk Factors Questionnaire were implemented. The results determined a direct relation between the Commuting to Work dimension of psychosocial risk factors and the MBI Burnout Syndrome ( $\mathrm{rp}=0.23 ; \mathrm{rp}=0.21 \mathrm{y} \mathrm{rp}=-0.23 ; p<0.05)$. The data classified $10 \%$ of the participants at a severe level of low Personal Realization in combination with Social Situations and Commuting of the psychosocial risk factors. They also reported Emotional Exhaustion of the burnout syndrome. Conclusion: The percentage of dentists with a high burnout level was similar to that reported in other studies and showed a significant relationship with Commute Situations as a psychosocial risk factor.
\end{abstract}

\section{Keywords}

Burnout, Emotional Exhaustion, Stress, Dentists

\section{Introduction}

These days evaluating the burnout syndrome on professionals providing health services is key to timely diagnosis y intervention in the work context. Its tridimensional acceptance (emotional exhaustion, depersonalization and cynicism) have produced two theoretical schools of thought: those who consider it a condition due to the consequences of chronic work stress (Grau, Flichtentrei, Suñer, Prats, \& Braga, 2009), or as an initial process due to stressful work conditions and the lack of institutional support, triggering non-adaptive responses by the 
worker (Castro, 2013; Gil-Monte, 2005; Martinez-Perez, 2010).

Conceiving the burnout syndrome as a process demands an analysis of the interaction between personal aspects (emotional, cognitive and attitudinal) and the worker's psychological resources or specific material (Abdulghafour, Bo-Hamra, Kamel, \& El-Shazly, 2011; Diaz-Bambula, Lopez-Sanchez, \& Varela-Arevalo, 2012; Tejada \& Gomez, 2012). Different investigations consider the burnout syndrome basically as exhaustion in the face of stress conditions brought on by work activities that triggers a series of negative health consequences (Ríos, Reyes, López, Morillo, \& Bullón, 2010; Moreno-Jimenez, Garrosa, \& Rodriguez, 2009) such as alienation and depersonalization (the second dimension in the concept of this syndrome), a response that depends on the particular activity performed by the professional (Moreno, Galvez, Garrosa, \& Mingote, 2006). Furthermore, the balance between work demands, expectations and achieving goals at work will also determine the satisfaction of achievement (the third dimension). It should be underscored that in the manifestation process of the burnout process, it is important to know the presence of previous and non-work conditions that, when combined with the traits of the organization, create the worker's particular responses.

Therefore, the Demand-Resource model (Demerouti, Bakker, \& Schaufeli, 2001; Bakker \& Demerouti, 2007) and the Effort-Reward model (Chandola, Siegrest \& Marmot, 2005) offer explanatory elements of the genesis of this ailment. These models identify different incident stress factors such as work overload, organizational conditions or work establishment, the lack of evidence of a work performance recognition process, inequity and interaction with non-work situations experienced by workers that, to the extent of their chronicity, generate the burnout symptomology (Diaz-Bambula et al., 2012; Finney, Stergiopoulos, Hensel, Bonato, \& Dea, 2013; Torres \& Guarino, 2013; Zhang \& Feng, 2011; Martinez-Perez, 2010).

Different studies have shown the importance of timely diagnosis of the burnout syndrome in health professionals whose primary activity is to provide assistance or health services to others, mainly because it may hinder interpersonal relations at work and create conflicts resulting in the appearance of physical symptoms as well as negative attitudes towards those whom they are attending (Lee et al., 2011; Ochomogo \& Barrera, 2011; Leon-Rubio, Leon-Perez, \& Cantero, 2011; Millan \& D’Aubeterre, 2012; Robles \& Casares, 2010).

Some researchers have studied personal psychosocial variables that are considered protective from burnout such as engagement, motivation, work satisfaction and self-efficacy (Zhang \& Feng, 2011) while others mention negative consequences such as emotional discomfort, absenteeism, depression and anxiety (Rios, Reyes, Lopez, Morillo, \& Bullon, 2010; Leon-Rubio, Cantero, \& Leon-Perez, 2011), or organizational variables such as an activity overload, negative perception of the organizational environment, job ambiguity, job seniority and decision-making autonomy among others (Patlán, 2012; Castañeda \& Garcia, 2013; Gopalan, Culbertson, \& Leiva, 2013). Nevertheless, few reports link social non-work variables to the burnout syndrome, such as life satisfaction, economic autonomy, negative changes to vital events, etc.

The dentistry profession is particularly recognized as highly stressful due to its treatment of users reacting with fear or anguishing over treatment, and exposure to occupational risks such as noise, temperature, specific postures, the chemical substances they handle and work overload in some cases among others (Ibañez, Bicenty, Thomas, \& Martinez, 2011; Pozos-Radillo, Preciado, Plascencia, Acosta, \& Aguilera, 2015; Saliba-Garbin, Reis dos Santos, Fagundes-Freire, \& Gonzalvez, 2011). And if you link it to commuting conditions, especially in urban areas with scarce public transportation designs, roads not apt for automobiles or limited parking spaces, they can be associated with the burnout of these professionals.

Therefore the objective of this study was to determine the association between the perception of personal social risk factors and commuting to work with the dimensions of the burnout syndrome in dentists working in the downtown area of Guadalajara, Jalisco, Mexico.

\section{Method}

\subsection{Participants}

An analytical cross sectional study was made of 144 dentists working in the downtown area of Guadalajara, Mexico during the period of 2013-2014. It should be mentioned that the conditions were peculiar at the time of the evaluation due to parking, mobility and living limitations plus infrastructure works being executed to remodel the design of a XVII century city to meet the demands of what it has turned into, third place in the country's economy; said works are supposed to be finished by in 2017. Sixty-two percent of the participants (89) were women and 38\% (55) men. Seventy-one percent (102) said they were married or in a commitment with someone. 
Of these, $43 \%$ (61) provided economic support to 1 to 3 people while $21 \%$ (30) more than three people. Twelve percent (18) of the $29 \%$ (42) single participants said they had 1 to 3 economic dependents. Sixty-four percent (92) said they owned their home outright, $14 \%$ (20) had a mortgage on their home and $22 \%$ (32) paid rent.

All the surveyed parties held a Degree in Dentistry with an average of $16(\mathrm{SD}=10.4)$ years of professional seniority. Two dentists (2\%) said they worked three days a week for 10 to 12 continuous hours at their office; $49 \%$ (70) said they worked 5 days a week for 8 to 12 hours and another 49\% (70) worked six days a week for 8 to 10 hours. Two participants who worked at the own office also mentioned having another full-time employment as teachers, working for 50 hours spread out over six days a week.

\subsection{Instruments}

\section{Maslach Burnout Inventory (MBI)}

The inventory adapted by Seisdedos (1997) was used to evaluate three dimensions: emotional exhaustion (EE), depersonalization (DP) and low self-realization at work (SR). It comprises 22 questions, with response options in scale from 0 to 6 points. A high Cronbach reliability is reported for EE 0.90, DP 0.79 and SR 0.71 with a factorial validity $(0.58 ; 0.36$; and -0.15 respectively) and convergence with different variables.

\section{Psychosocial Risk Factor Questionnaire in Workers (PRFQW)}

This questionnaire, expressly designed for this investigation, was used to evaluate three dimensions: a) social or commuting aspects, b) personal aspects and c) way conditions (home-work-home) that workers refer to as stressful. It includes 27 questions with dichotomous response options (Yes-No). Each dimension consists of nine items where an affirmative answer has a value of one and a negative answer zero; thus the sum score of items per dimension weighs the number of events mentioned as stressful in each dimension. Preliminary studies showed sensitivity above 0.47 and specificity above 0.85 . The reliability for the commuting dimension was Cronbach 0.50 alpha for the social dimension and 0.22 alpha for the personal dimension (Appendix).

\subsection{Procedure}

Dental offices were located in the downtown area of the city of Guadalajara. We proceeded to survey the dentists who were working on the day of the visit, beginning in the first quadrant until the outskirts of four square kilometers. Participation was voluntary with a semi structured interview lasting approximately 45 minutes covering social, academic and work data. The activity was performed between September 2013 and February 2014.

The variables measured on a nominal scale were analyzed with percentage distributions while variables on a numeric scale with measurements of central tendency, arithmetic mean variance and standard deviation. The relationship between the psychosocial risk factors and the burnout syndrome was calculated with Pearson $r$ with a significant value of $p \leq 0.05$. Data were analyzed with IBM-SPSS software (version 19, USA) under the university's license.

The protocol of this study was registered under number C1-11308 by the Evaluation and Ethics Committees of the University of Guadalajara. The investigation was carried out with the voluntary informed consent of the participants. The work was compliant with the General Regulations of the General Health Act for the area of Health Research in Mexico (RLGS, 1986) and compliant with the Declaration of Helsinki (2013).

\section{Results and Findings}

Of the 144 dentists evaluated with MBI, 34 (24\%) of the participants showed a high level of emotional exhaustion, described a sensation of "having no more to give of themselves", of feeling worn out when expressing their emotions. High levels of the depersonalization dimension or the indifferent treatment of users were recorded in 39 (27\%) of the participants. Lastly, low self-realization was recorded in 69\% (99) of the dentists with a low level of feeling low professional competency and success in treating their patients (Table 1).

The perception of stressful social situations was recorded in $83 \%$ (120) of the surveyed dentists who said they had no time to talk to their neighbors or were unable to organize leisure or fun activities with their family. In the personal aspect dimension, 95\% (137) were recorded in risk situations due to lack of planning their immediate future and perceiving disorder at home. The commuting dimension (home-work-home) recorded 86\% (124) at risk because of their concern of arriving late to work due to slow transportation and because they often break traffic laws (Table 2). 
Table 1. Level of stress burnout syndrome on dentists working in the downtown area of Guadalajara, Mexico (2013-2014).

\begin{tabular}{ccccccc}
\hline & \multicolumn{2}{c}{ Emotional Exhaustion } & \multicolumn{2}{c}{ Depersonalization } & \multicolumn{2}{c}{ Personal Accomplishment } \\
\cline { 2 - 6 } Risk & $\mathrm{n}$ & $\%$ & $\mathrm{n}$ & $\%$ & $\mathrm{n}$ & $\%$ \\
\hline Low & 45 & 31 & 33 & 23 & 17 & 12 \\
Half & 65 & 45 & 72 & 50 & 28 & 99 \\
High & 34 & 24 & 39 & 27 & 99 & 69 \\
\hline
\end{tabular}

Note: $\mathrm{N}=144$. The Maslach Burnout Inventory version of Seisdedos, 1997.

Table 2. Psychosocial factors perceived as a source of stress on dentists working in the downtown area of Guadalajara, Mexico (2013-2014).

\begin{tabular}{|c|c|c|c|c|c|c|}
\hline \multirow[b]{3}{*}{ Risk } & \multirow{2}{*}{\multicolumn{2}{|c|}{ Social Situations }} & \multirow{2}{*}{\multicolumn{2}{|c|}{ Personal Aspects }} & \multicolumn{2}{|c|}{ Way } \\
\hline & & & & & \multicolumn{2}{|c|}{ (home-work-home) } \\
\hline & $\mathrm{n}$ & $\%$ & $\mathrm{n}$ & $\%$ & $\mathrm{n}$ & $\%$ \\
\hline Low & 24 & 17 & 7 & 5 & 20 & 14 \\
\hline High & 120 & 83 & 137 & 95 & 124 & 86 \\
\hline
\end{tabular}

Note: $\mathrm{N}=144$. Psychosocial Risk Factors Quiestionnaire in Workers.

The data were analyzed with Pearson $r$ statistics and it was determined that the commuting dimension (home-work-home) was associated with the MBI dimensions. Furthermore, the personal aspect dimension has a significant inverse relationship with the MBI Depersonalization dimension (Table 3).

Table 4 shows the distribution of participants according to the combination of risk levels in the dimensions of the Occupational Psychosocial Risk Factor Questionnaire. We should underscore that 10\% (14) of the participants reported being at risk due to commuting conditions in combination with low self-realization while $12 \%$ (17) mentioned it is due to the situations they face in their social setting.

\section{Discussion}

A significant statistical relationship was determined in this study between psychosocial risk factors due to commuting situations perceived as stressful and the emotional exhaustion dimension of the burnout syndrome. Difficult traffic experiences, the lack of parking spaces for the vehicles driven by the surveyed professionals as well as contamination in the city are likely important aspects in their manifestation of exhaustion. One can see that a worker may arrive at his or her workplace with a prior load of emotional reactions that exacerbate working conditions that are also a source of stress.

This suggests that in the context of this investigation, psychosocial factors external to work activities experienced as stressors have a close relationship with emotional exhaustion at work and the manifestations of burnout syndrome-related symptomology. This is consistent with the models created by researchers including Önder \& Basim (2008), Sanin \& Salanova (2014), Gopalan, Culbertson, \& Leiva (2013), Leon-Rubio, LeonPerez, \& Cantero (2013) among others.

The psychosocial factor of commuting (home-work-home) perceived as a stressor in this study showed high scores in the participants although no significant relationship was maintained with the Depersonalization and the Self-Realization dimensions of the burnout syndrome. This factor is considered to be a potentially dangerous condition in our country for worker protection and is legally classified (Mexico's Federal Labor Law). We should highlight that there are few studies associating commuting conditions with the burnout syndrome. For example, Marinaccio et al. (2013) mentions that commute time (lasting more than an hour) and the work shift seem to be associated with greater levels of risk for stress. But it is incompatible with the results offered by Nivens \& Nordstrom (2012) who studied the effects of driving a vehicle to work. Those data say there is no significant relationship with stress and the burnout syndrome. Nonetheless and not unlike other studies, it is suggested in the context of this study that psychosocial factors external to work activities experienced as stressors 
Table 3. Correlation between psychosocial factors and stress burnout syndrome on dentists working in the downtown area of Guadalajara, Mexico (2013-2014).

\begin{tabular}{|c|c|c|c|c|c|}
\hline \multirow{2}{*}{ Factor } & \multirow{2}{*}{\multicolumn{2}{|c|}{ Statistics }} & \multicolumn{3}{|c|}{ Burnout Syndrome (MBI) } \\
\hline & & & $\mathrm{EE}$ & $\mathrm{D}$ & LPA \\
\hline \multirow{4}{*}{ Path (home-work-home) } & \multicolumn{2}{|c|}{ r Pearson’s } & 0.233 & 0.206 & -0.226 \\
\hline & \multicolumn{2}{|c|}{ p (two-trailed) } & 0.005 & 0.013 & 0.006 \\
\hline & \multirow[t]{2}{*}{ CI 95\% } & Low & 0.077 & 0.058 & -0.379 \\
\hline & & High & 0.393 & 0.359 & -0.074 \\
\hline \multirow{4}{*}{ Socials Situations } & \multicolumn{2}{|c|}{ r Pearson's } & -0.087 & -0.076 & 0.079 \\
\hline & \multicolumn{2}{|c|}{ p (two-trailed) } & 0.298 & 0.364 & 0.345 \\
\hline & \multirow[t]{2}{*}{ IC 95\% } & Low & -0.255 & -0.251 & -0.074 \\
\hline & & High & 0.075 & 0.093 & 0.237 \\
\hline \multirow{4}{*}{ Personals Aspects } & \multicolumn{2}{|c|}{ r Pearson’s } & -0.128 & -0.178 & -0.119 \\
\hline & \multicolumn{2}{|c|}{ p (two-trailed) } & 0.126 & 0.033 & 0.154 \\
\hline & \multirow[t]{2}{*}{ IC $95 \%$} & Low & -0.290 & -0.331 & -0273 \\
\hline & & High & 0.027 & -0.007 & 0.039 \\
\hline
\end{tabular}

Note: $\mathrm{N}=144$. CI = Confidence Interval. $\mathrm{EE}=$ Emotional Exhaustion; $\mathrm{D}=$ Depersonalization; LPA = Low Personal Accomplishment.

Table 4. Classification by risk level and factors psychosocial on dentists working in the downtown area of Guadalajara, Mexico (2013-2014).

\begin{tabular}{|c|c|c|c|c|c|c|c|c|c|c|c|c|c|}
\hline \multirow{2}{*}{ MBI } & & \multicolumn{4}{|c|}{ Social Situations } & \multicolumn{4}{|c|}{ Personal Aspects } & \multicolumn{4}{|c|}{ Path (home-work-home) } \\
\hline & & $(+)$ & $\%$ & $(-)$ & $\%$ & $(+)$ & $\%$ & $(-)$ & $\%$ & $(+)$ & $\%$ & $(-)$ & $\%$ \\
\hline \multirow{3}{*}{$\mathrm{EE}$} & Low & 11 & 8 & 34 & 24 & 0 & 0 & 45 & 31 & 2 & 1 & 43 & 30 \\
\hline & Half & 9 & 6 & 56 & 39 & 4 & 3 & 61 & 42 & 13 & 9 & 52 & 36 \\
\hline & High & 4 & 3 & 30 & 21 & 3 & 2 & 31 & 22 & 5 & 4 & 29 & 20 \\
\hline \multirow{3}{*}{$\mathrm{D}$} & Low & 6 & 4 & 27 & 19 & 0 & 0 & 33 & 23 & 3 & 2 & 30 & 21 \\
\hline & Half & 13 & 9 & 59 & 41 & 2 & 1 & 70 & 49 & 8 & 6 & 64 & 44 \\
\hline & High & 5 & 4 & 34 & 24 & 5 & 4 & 34 & 24 & 9 & 6 & 30 & 21 \\
\hline \multirow{3}{*}{ LPA } & Low & 3 & 2 & 14 & 10 & 0 & 0 & 17 & 12 & 3 & 2 & 14 & 10 \\
\hline & Half & 4 & 3 & 24 & 17 & 1 & 1 & 27 & 19 & 3 & 2 & 25 & 17 \\
\hline & High & 17 & 12 & 82 & 57 & 6 & 4 & 93 & 65 & 14 & 10 & 85 & 59 \\
\hline
\end{tabular}

Note: $\mathrm{N}=$ 144. $\mathrm{EE}=$ Emotional Exhaustion; $\mathrm{D}=$ Depersonalization; LPA $=$ Low Personal Accomplishment. $(+)=$ Risk, $(-)=$ No Risk.

may exacerbate the relationship with emotional exhaustion at work and with the symptomology associated with the burnout syndrome (Montero-Marin, Araya, Olivan, Skapinakis, Martinez, \& Garcia, 2012).

It is important to consider the three-dimensional structure of the burnout syndrome as a process in keeping with the phases proposed by theoreticians, in which the fundamental indicator is in the high scores of the emotional exhaustion dimension. The results of this study were similar to those reported by Visoso et al. (2012) in his study of dentistry teachers at a Mexican university, and they are congruent with the average data reported in other samplings in this country (Juarez-Garcia, Idrovo, Camacho-Avila, \& Placencia-Reyes, 2014).

They are also similar to the percentages of high burnout levels in dentists at different institutions in other regions, as reported by Robles \& Casares (2010) who analyzed the relationship with health problems (without 
specifying which). The variables of hiring, fixed shift and more than 10 years seniority (work conditions) are related to the burnout syndrome as reported in a study by Castañeda \& Garcia (2013) with dentists providing social care and treating the university community. Nevertheless, the average parameters reported are below the normal cutoff point although the percentage (52\%) that it specifies as risky for the syndrome is higher than what is reported here.

Nevertheless, the levels of burnout syndrome reported here are higher than those of other Latin American populations (Millan \& D’Auberterre, 2012; Ochomogo \& Barrera, 2011). Possibly the percentages of professionals affected by the burnout syndrome vary from other studies due to the fact that the information-gathering method is reported in very diverse ways (Schaufeli \& Taris, 2005). Nonetheless, this study tried to limit possible biases in administering the questionnaires by observing the procedures indicated in the manuals and obtaining information during semi structured interviews face to face with the participants, which the authors consider a strength in the consistency of the analyzed data.

Like all observational and cross sectional studies, this one has several limitations given that the information was gathered with self-report questionnaires (where the answer is evaluated by the respondent). Besides, the stress coping pattern and other socioeconomic or demographic factors that may interact with the burnout syndrome response were not assessed. Future research should include objective measures from the viewpoint of those who make up the social networks at work (colleagues and superiors) as well as studies including an analysis of clinical histories and workplace and environmental conditions that may play a role in the presence of burnout symptomology.

\section{Conclusion}

A statistically significant relationship was determined between psychosocial risk factors due to commuting to work perceived as a stressor and the emotional exhaustion dimension of the burnout syndrome. Between $4 \%$ and $10 \%$ of dentists showed to be at risk due to social and personal aspects and commuting in combination with a high level of emotional exhaustion, depersonalization and low achievement realization. The study contributes by showing the interaction of non-work psychosocial factors (commuting) with the burnout syndrome dimensions, thereby contributing to the theoretical concept of the syndrome process.

\section{Acknowledgements}

A grant given for the project titled "Occupational emotional exhaustion of public sector health professionals in the metropolitan area of Guadalajara. Mexico”; Code 119561 from CONACYT-UdG for the 2009-2013 period.

\section{Conflict of Interest}

The authors declare that there is no conflict of interests in connection with this investigation, the authorship and/or the publication of this article.

\section{References}

Abdulghafour, Y., Bo-Hamra, A. M., Al-Randi, M. S., Kamel, M. I., \& El-Shazly, M. K. (2011). Burnout Syndrome among Physicians Working in Primary Health Care Centers in Kuwait. Alexandria Journal of Medicine, 47, 351-357. http://dx.doi.org/10.1016/j.ajme.2011.08.004

Bakker, A. B., \& Demerouti, E. (2007). The Job Demands-Resources Model: State of the Art. Journal of Managerial Psychology, 22, 309-328. http://dx.doi.org/10.1108/02683940710733115

Castañeda, E., \& García de Alba, J. (2013). Prevalence of Professional Burnout Syndrome among Dentists in the Education and Health Sectors in the City of Guadalajara, Mexico, 2012. Revista Facultad de Odontología Universidad de Antioquia, 24, 267-288. http://dx.doi.org/10.1136/oem.2004.016675

Castro, F. G. (2013). Burnout and Historical Complexity. Revista Psicologia: Organizações e Trabalho, 13, 49-60.

Declaration of Helsinki AMM (2013). Ethical Principles for Medical Research Involving Human Subjects. http://www.wma.net/es/30publications/10policies/b3/

Demerouti, E., Bakker, A. B., Nachreiner, F., \& Schaufeli, W. B. (2001). The Job Demands-Resources Model of Burnout. Journal of Applied Psychology, 86, 499-512. http://dx.doi.org/10.1037/0021-9010.86.3.499

Diaz-Bambula, F., López-Sánchez, A. M., \& Varela-Arévalo, M. T. (2012). Factors Associated to Burnout Syndrome in High School Teachers in Cali, Colombia. Universitas Psychologica, 11, 217-227. 
Finney, C., Stergiopoulos, E., Hensel, J., Bonato, S., \& Dewa, C. S. (2013). Organizational Stressors Associated with Job Stress and Burnout in Correctional Officers: A Systematic Review. BMC Public Health, 13.

http://www.biomedcentral.com/1471-2458/13/82

http://dx.doi.org/10.1186/1471-2458-13-82

Gil-Monte, P. (2005). El síndrome de quemarse por el trabajo (burnout). An Occupational Disease in the Welfare Society. Ediciones Pirámide.

Gopalan, N., Culbertson, S .S., \& Leiva, P. I. (2013). Explaining Emotional Labor's Relationships with Emotional Exhaustion and Life Satisfaction: Moderating Role of Perceived Autonomy. Universitas Psychologica, 12, 347-356.

http://www.scielo.org.co/scielo.php?script=sci_arttext\&pid=S1657-92672013000200003 http://dx.doi.org/10.11144/Javeriana.UPSY12-2.eelr

Grau, A., Flichtentrei, D., Suñer, R., Prats, M., \& Braga, F. (2009). Influence of Personal, Professional and Cross-National Factors in Burnout Syndrome in Hispanic Americans and Spanish Health Workers (2007). Revista Española de de Salud Pública, 83, 215-230. http://dx.doi.org/10.1590/S1135-57272009000200006

Ibañez, E., Bicenty, A., Thomas, Y., \& Martinez, J. (2011). Prevalence and Associated Factors in Burnout Syndrome on Professors of the Fundación Universitaria San Martín, 2011. Revista Colombiana de Enfermería, 7, 105-111.

Juarez-Garcia, A., Idrovo, A. J., Camacho-Ávila, A., \& Placencia-Reyes, O. (2014). Burnout Syndrome in Mexican Population: A Systematic Review. Salud Mental, 4, 159-176.

Lee, S., Oguienko, O., Song, B., Sunderji, S., Wong, J., Zhao, X., Versloo, J., \& Azarpazhoo, A. (2011). Risk Factors for Burnout among Dentists: An Evidence-Based Study of the Literature. Toronto: University of Toronto, Faculty of Dentistry. https://www.dentistry.utoronto.ca/system/files/y3_2011.pdf

Leon-Rubio, J. M., Cantero, J., \& León-Pérez, J. M. (2011). Working Conditions and Differences in the Role That Self-Efficacy Plays in the Burnout Perceived by University Staff. Revista Anales de Psicología, 27, 518-526.

Leon-Rubio, J. M., León-Pérez, J. M., \& Cantero, F. (2013). Prevalence Rate and Predictive Factors of Burnout among Public Education Teachers: The Role of Gender. Ansiedad y Estrés, 19, 11-25.

Marinaccio, A., Ferrante, P., Corfiati, M., Di Tecco, C., Rondinone, B. M., Bonafede, M., \& .Iavicoli, S. (2013). The Relevance of Socio-Demographic and Occupational Variables for the Assessment of Work-Related Stress Risk. BMC Public Health, 13, 1-18. http://dx.doi.org/10.1186/1471-2458-13-1157

Martinez-Perez, A. (2010). The Burnout Syndrome. Overview and Development of the Concept. Vivat Academia, 6, 28-52. http://www.ucm.es/info/vivataca/numeros/n112/DATOSS.htm

Millan, A., \& D’Aubeterre, M. (2012). Psychometric Properties of the Questionnaire of Working Conditions (QCT) in a Multi-Occupational Venezuelan Sample. Revista de Psicología, 30, 103-128.

Montero-Marin, J., Araya, R., Olivan, B., Skapinakis, P., Martinez, V., \& García-Campayo, J. (2012). Understanding Burnout according to Individual Differences: Ongoing Explanatory Power Evaluation of Two Models for Measuring Burnout Types. MBC Public Health, 12, 1-12. http://www.biomedcentral.com/1471-2458/12/922

http://dx.doi.org/10.1186/1471-2458-12-922

Moreno-Jimenez, B., Garrosa, E., Rodríguez, R., Martínez, M., \& Ferrer, R. (2009). Burnout among faculty Members and the Intentions to Quit: A Multi-Sample Study. Revista de Psicología del Trabajo y de las Organizaciones, 25, 149-163.

Nivens, V., \& Nordstrom, C. R. (2012). The Effect of Workers’ Driving Commute on Stress and Burnout. Psychology Journal, 9, 73-83.

Ochomogo, H., \& Barrera, E. (2011). Prevalence of Burnout in Staff of the National Mental Health Hospital of Guatemala. Revista Latinoamericana de Psiquiatría, 10, 11-17.

Önder, C., \& Basim, N. (2008). Examination of Developmental Models of Occupational Burnout Using Burnout Profiles of Nurses. Journal of Advances Nursing, 64, 514-523. http://dx.doi.org/10.1111/j.1365-2648.2008.04818.x

Patlán, J. (2012). Effect of Organizational Climate and Work Overload in Burnout. Rev Mex Sal Trab, 4, 62-64.

Pozos-Radillo, B. E., Preciado, M. L., Plascencia, A. R., Acosta, M., \& Aguilera, M. A. (2015). Academic Stress and Physical, Psychological and Behavioral Factors in Mexican Public University Students. Ansiedad y Estres, 21, 35-42.

Ríos-Santos, J., Reyes-Torres, M., Morillo-Velázquez, J. M., \& Bullón, P. (2010). Burnout and Depression among Spanish Periodontology Practitioners. Medicina Oral, Patología Oral y Cirugía Bucal, 15, e813-e819. http://dx.doi.org/10.4317/medoral.15.e813

RLGS (1986). Regulation of the General Law of Health in Research for Health. http://www.salud.gob.mx/unidades/cdi/nom/compi/rlgsmis.html

Robles, R., \& Cáceres, L. (2010). Burnout Syndrome in Dental Surgeons from Lima Metropolitan Hospitals. Odontología Sanmarquia, 13, 7-10. 
Saliba-Garbin, C. A., Isper-Gargin, A. J., Reis dos Santos, R. R., Fagundes-Freire, A. C. G., \& Gonzalvez, P. E. (2011). Burnout's Syndrome in Dentists. Journal of Depression \& Anxiety, 1.

Sanin, J. A., \& Salanova, M. (2014). Job Satisfaction: The Way between Psychological Growth and Job Performance in Industrial and Service Companies in Colombia. Universitas Psychologica, 13, 95-107.

Schaufeli, W., \& Taris, T. W. (2005). The Conceptualization and Measurement of Burnout: Common Ground and Worlds Apart. Work \& Stress, 19, 256-262. http://dx.doi.org/10.1080/02678370500385913

Seisdedos, N. (1997). MBI: Maslach Burnout Inventory. S. A. Madrid: Department of I-D de TEA Editions.

Tejada, P., \& Gómez, V. (2012). Prevalence and Both Demographic and Work Factors Associated with Burnout of Psychiatrists in Colombia. Universitas Psychologica, 11, 863-873. http://www.redalyc.org/pdf/647/64724634015.pdf

Torres, B., \& Guarino, L. (2013). Individual Differences and Burnout in Venezuelan Oncologists. Universitas Psychologica, 12, 95-104.

Visoso, A., Sánchez, A., \& Montiel, M. (2012). Burnout Syndrome in the Faculty of Dentistry, Autonomous Mexico State University: A Comparative Study. International Journal of Odontostomatology, 6, 129-138.

Zhang, Y., \& Feng, X. (2011). The Relationship between Job Satisfaction, Burnout, and Turnover Intention among Physicians from Urban State-Owned Medical Institutions in Hubei, China: A Cross-Sectional Study. BMC Health Services Research, 11, 2-13. http://www.biomedcentral.com/1472-6963/11/235

http://dx.doi.org/10.1186/1472-6963-11-235 


\section{Appendix}

Psychosocial Risk Factor Questionnaire in Workers

1. Do you commute to work from another city or town?

2. Do you feel unsafe on the streets you drive down?

3. Are there are difficulties for you to commute to work or from work to your home?

4. Do you worry about arriving late to work?

5. Do you feel nervous and anxious while waiting for transportation when going to work?

6. Do you feel restless due to slow traffic on the way to work or from work to your home?

7. Are you upset about traffic laws being broken if you are on transportation to work or from work to your home?

8. Have you ever arrived late at work due to commute complications from your home?

9. Have you ever had an accident while commuting (home-work-home)?

10. Have you ever been unemployed for more than a month?

11. Are you currently studying and working (and have to fulfill both conditions)?

12. Do you have any economic debts from a loan or mortgage that worries you?

13. Do you live alone?

14. Do you like to talk to your neighbors?

15. Do you spend time with people with alcohol, addiction or legal problems?

16. Do you organize your free time with recreational activities? (Trips, movies, sports, music, etc.)

17. Do you enjoy being with relatives on a regular basis?

18. Do you speak to professionals about your problems?

19. FOR WOMEN: Have you ever had an unwanted pregnancy? FOR MEN Have you taken responsibility for unwanted children?

20. Do you have any serious or chronic disease?

21. Have you experienced an important separation (mourning) during the last six months?

22. Do you sleep enough to feel rested?

23. Do you reject things you cannot do or that are beyond the scope of your responsibilities?

24. Do you have any specific plans for the next six months?

25. Do you usually take care of your health (mental and physical)?

26. Do you combine physical exercise with good eating habits?

27. Do you feel your home is in order and clean? (Both combinations) 